\title{
Políticas públicas e desenvolvimento urbano sustentável
}

\section{Public policies and urban sustainable development}

\author{
Paulo Rolando de LIMA ${ }^{1}$ \\ Eduardo L. KRÜGER ${ }^{2}$
}

RESUMO

Considerando que o processo de desenvolvimento urbano implica na multiplicação dos impactos ambientais decorrentes do assentamento humano sobre a área de influência da cidade e a existência de diretrizes de ação visando à promoção da sustentabilidade urbana na Agenda 21 brasileira, bem como nas disposições do Estatuto da Cidade, especialmente no que se refere aos objetivos da política urbana, garantia do direito a cidades sustentáveis, planejamento do desenvolvimento urbano, estudo de impacto de vizinhança e ao Plano Diretor, o trabalho aponta possibilidades de efetivação destas diretrizes e dispositivos legais no gerenciamento urbano por meio de políticas públicas locais no âmbito dos transportes, habitação e uso do solo. Tais políticas deverão estar dirigidas a objetivos ambientais definidos em função do grau de qualidade ambiental urbana presente e da eqüidade da sua distribuição espacial, visando a uma situação futura desejada.

Palavras-chave: sustentabilidade urbana, urbanismo, gestão urbana.

\begin{abstract}
Considering that urban development is directly related to the spreading of environmental impacts caused by human settlements within city limits and the existence of directives in the Brazilian Agenda 21 regarding the promotion of urban sustainability, as well as the content of the City Statute regarding urban policies towards sustainable cities and urban planing, this study presents possibilities of implementing directives and legal measures for urban management by means of local public policies concerning transportation, habitation and land use. Such policies should be directed towards environmental objectives, defined with regard to the present urban environmental quality and spatial distribution, aiming at a desired future condition.

Key-words: urban sustainability, urban planing, urban management.
\end{abstract}

\footnotetext{
1 Arquiteto, Mestre em Tecnologia-CEFET-PR. Departamento Acadêmico de Construção Civil. Centro Federal de Educação Tecnológica do Paraná - CEFET-PR
} 2 Programa de Pós-Graduação em Tecnologia / Professor doutor do Departamento Acadêmico de Construção Civil - CEFET-PR <krueger@ppgte.cefetpr.br> 
LIMA, P. R. de; KRÜGER, E. L. Políticas públicas e desenvolvimento urbano sustentável

\section{Introdução}

A maioria da população brasileira reside nas cidades e grande parte das atividades humanas acontece no espaço urbano, fenômenos que tendem a continuar ocorrendo no futuro, provavelmente de forma mais intensa e acelerada. A perspectiva de crescimento das cidades acentua a necessidade de a sociedade buscar formas de tornar o processo de desenvolvimento urbano sustentável, de modo a evitar ou minimizar as alterações climáticas decorrentes da urbanização, reduzir a poluição ambiental e garantir a preservação ou a construção de um ambiente urbano saudável para as gerações presentes e futuras.

A sustentabilidade urbana há que ser encarada como um processo (BEZERRA; FERNANDES, 2000) no qual as ações do poder público e da comunidade no presente considerem e promovam uma situação desejável no futuro, observando cuidadosamente os resultados semeados no passado. Dependendo da matriz discursiva seguida, como analisou Acselrad (1999), a sustentabilidade urbana poderá ser definida em função da maior eficiência no uso dos recursos naturais, econômicos e financeiros, de um determinado limite de tamanho compatível com as características do sítio urbano ou ainda pela capacidade de distribuir eqüitativamente os benefícios e ônus da experiência urbana, oferecendo níveis adequados de qualidade de vida a todos os seus habitantes, no presente e no futuro.

Em qualquer das hipóteses, é indispensável que as políticas públicas incorporem a preocupação com a manutenção e aprimoramento da qualidade ambiental da cidade, estabelecendo objetivos ambientais para os quais as ações da administração pública e da sociedade devam convergir, de forma que o resultado das intervenções presentes não venha a comprometer as condições ambientais e de atendimento às demandas por infra-estrutura e qualidade de vida no futuro.

Nesse processo, certamente o papel da organização e controle do uso e ocupação do solo urbano será preponderante, dada a sua capacidade de influir sobre a localização de atividades, a distribuição da densidade populacional, a geração de tráfego, etc., tanto que mereceu atenção considerável na formulação da Agenda 21 brasileira e no próprio Estatuto da Cidade.

Se comprometidas com a sustentabilidade, as políticas de uso e ocupação do solo urbano que norteiam as diretrizes dos Planos Diretores e Leis de Zoneamento precisam embutir esse compromisso nas prescrições de usos mais ou menos adequados para uma determinada zona, na definição das taxas de ocupação, coeficientes de aproveitamento, recuos e afastamentos obrigatórios, taxas de permeabilidade e outros parâmetros que orientam a localização de atividades e as iniciativas de construção.

O presente estudo aborda a possibilidade de utilizar os parâmetros de uso e ocupação do solo como um dos instrumentos de implementação de processos de desenvolvimento urbano sustentável.

\section{Uso e ocupação do solo e o futuro das cidades.}

A cidade moderna é o local onde as pessoas procuram viver e para isso se obrigam ao exercício de atividades que se enquadram entre as funções urbanas identificadas na clássica Carta de Atenas: Habitar, Trabalhar, Circular e Recrear-se. Sempre atendendo a uma diretriz mais abrangente, a definição das atividades que poderão se instalar em uma determinada área da cidade deve procurar sintonizar as demandas do processo de desenvolvimento com a preservação da qualidade ambiental desta mesma área e do bem-estar de seus habitantes e usuários.

O uso do solo urbano, segundo Ferrari (1979), pode ser classificado como residencial, industrial, comercial e de serviços, institucionais públicos ou privados, áreas de circulação e áreas vagas.

As proporções entre os tipos de uso do solo em experiências citadas por Ferrari (1979) revelam que o uso residencial predomina no conjunto das cidades. Os demais usos (comercial, industrial, etc.) geralmente respondem às necessidades das pessoas que utilizam a cidade para residir, oferecendo produtos e serviços indispensáveis a sua sobrevivência, gerando riquezas, empregos, excedentes, etc., de modo que, para ter sustentabilidade, uma cidade precisa garantir um certo equilíbrio entre os diversos usos, inclusive no que se refere à distribuição espacial.

Nesta linha, no caso de cidades já consolidadas, é conveniente monitorar a evolução da proporção entre os diversos usos e, além disso, a distribuição espacial destes de forma a permitir verificar, por exemplo, se a participação do uso do solo para fins comerciais e industriais em uma determinada área atende adequadamente à demanda por empregos, produtos e serviços da população nela residente ou até se as áreas de circulação são compatíveis com o tráfego gerado pela implantação gradativa e futura dos usos residenciais, comerciais e industriais admitidos pela norma legal vigente. 
Na escala do bairro, é possível e conveniente analisar a situação instalada do uso e da ocupação do solo para checar se, ao definir limites para as intervenções de iniciativa pública ou privada, os parâmetros legais estabelecidos são capazes de assegurar a sustentabilidade da cidade ou se a efetiva aplicação de suas prescrições poderá comprometer algum objetivo ambiental no futuro.

Para essa tarefa, o planejador poderá utilizar indicadores fornecidos pela literatura técnica ou por experiên cias de outras cidades aplicáveis à realidade em estudo, na análise das potenciais interferências que o crescimento futuro, moldado pelas normas da Lei de Zoneamento, produzirá na qualidade do ambiente e bem-estar dos cidadãos.

Nes se sentido, e considerando que o desenvolvimento de qualquer atividade humana na área urbana implica na geração de resíduos e efluentes sólidos, líquidos e gasosos, bem como no consumo de energia, é conveniente que os parâmetros de uso e da ocupação do solo contribuam para reduzir os efeitos destes fatores sobre 0 ambiente urbano ao longo do tempo, embutindo em sua zona de influência a limitação quantitativa e a distribuição espacial da produção de poluentes e fatores de degradação ambiental.

É possível simular a situação futura de uma cidade a partir dos parâmetros de uso e ocupação do solo que, a rigor, têm a finalidade de orientar a configuração do espaço urbano e, com base nos resultados da simulação, avaliar se a política de uso e ocupação do solo aponta para a sustentabilidade ou não. Admitindo-se como correta a premissa de que um determinado setor da cidade que possui uma Lei de Zoneamento, em algum momento futuro, terá o seu espaço passível de receber construção todo ocupado segundo os parâmetros dessa Lei, uma situação hipotética da configuração do bairro pode ser obtida a partir das seguintes relações:

- Área de lotes $/$ Taxa de ocupação = Área ocupada

- Área de lotes $/$ Taxa de permeabilidade = Área permeável

- Área de lotes $/$ Coeficiente de Aproveitamento= Área construída total

- Área construída / Área média dos imóveis = Número de unidades

- Número de unidades $/$ habitantes por domicílio $=$ População do bairro

- População do bairro / taxa de motorização= Número de veículos
As informações necessárias são facilmente obtidas nos órgãos responsáveis pelo licenciamento de veículos, cadastros técnicos e outras fontes estatísticas, sendo que a situação hipotética simulada permitirá uma avaliação aproximada da densidade demográfica, da densidade de construções, da produção de resíduos sólidos e líquidos e, conseqüentemente, das demandas por serviços e da pressão sobre o ambiente urbano.

Com a consciência das causas que provocam alterações no clima e a poluição ambiental nas áreas urbanizadas, estudos desta natureza evidenciam as possibilidades de adequação dos parâmetros de uso e ocupação do solo para acrescentar aos efeitos que deles se esperam a melhoria e preservação das qualidades ambientais da cidade e da sua capacidade de responder à demanda por serviços e infraestrutura urbana que garantam a qualidade de vida da população em níveis no mínimo iguais ao atual.

\section{Alterações climáticas decorrentes da urbanização}

A instalação de um núcleo urbano provoca significativas e definitivas modificações no ambiente natural, de início pela remoção da cobertura vegetal original seguida da alteração da topografia, abertura de ruas, implantação de edifícios, pavimentações, etc. Com o passar do tempo, esse processo provoca alterações no clima local, criando um conjunto de condições especiais que constituem o clima urbano.

O fluxo intenso de veículos motorizados, a concentração industrial, o adensamento de edificações, a verticalização das construções, a pavimentação de ruas e a diminuição de áreas verdes que se verificam nas cidades influem diretamente na composição química da atmosfera, no balanço hídrico e térmico (LOMBARDO, 1997). A dinâmica da vida urbana dissemina a criação de diversas fontes de calor, que se somam ao aquecimento dos recintos urbanos resultante da ação da radiação solar sobre materiais de construção e pavimentação que possuem boa condutividade térmica e capacidade calorífica.

A implantação das construções e o arruamento, comenta Lombardo (1997), resultam em uma superfície irregular que altera a movimentação do ar e o sistema de escoamento da água da chuva e, por conseqüência, diminui o efeito de resfriamento do ar urbano pela evaporação e facilita a concentração de material particulado no ar. Essa concentração, por sua vez, altera a incidência da energia radi- 
LIMA, P. R. de; KRÜGER, E. L. Políticas públicas e desenvolvimento urbano sustentável

ante do Sol, propicia o aparecimento de nuvens e enseja a formação de núcleos de condensação, modificando assim o regime de precipitações pluviométricas.

As alterações climáticas decorrentes da urbanização revelam-se claramente quando se confrontam elementos climáticos de uma área urbanizada com o que se verifica no seu entorno rural. Nas áreas urbanas, a radiação solar global é cerca de 15 a 20\% menor do que nas áreas rurais, a temperatura média anual de 0,5 a $1,0^{\circ} \mathrm{C}$ maior, a média anual da velocidade do vento é 20 a $30 \%$ menor, enquanto a incidência de calmarias é 5 a 20\% maior nas áreas urbanizadas, sendo a precipitação 5 a $10 \%$ mais intensa nas cidades que nas áreas rurais (LANDSBERG, 1970 apud ROMERO, 1988 ).

Tendo como cenário a Região Metropolitana de Curitiba, Krüger e Rossi (2002) constataram que a temperatura entre um ponto situado em área bastante adensada, localizada no centro de Curitiba, nos dias mais frios era até $4,0^{\circ} \mathrm{C}$ superior à temperatura registrada no mesmo momento na estação climatológica do Sistema Metereológico do Paraná (Simepar), situada em área pouco adensada no município de Pinhais, a menos de $15 \mathrm{~km}$ do outro ponto de medida. Nos dias mais quentes essa diferença também foi verificada, chegando a $1,8^{\circ} \mathrm{C}$.

As mudanças climáticas mencionadas contribuem para a degradação do ambiente urbano, com conseqüências óbvias sobre a saúde e o conforto dos habitantes, portanto suas causas precisam ser controladas antes que comprometam de forma irremediável a qualidade de vida nas cidades.

Uma forma de controle poderá se dar pela conciliação inteligente do comportamento e dos efeitos da movimentação do ar e da radiação solar com a necessidade de adaptar o ambiente para o exercício da vida urbana, quando da formulação e aplicação dos parâmetros de ocupação do solo urbano.

\section{A poluição no ambiente urbano}

Os esforços para a preservação do clima urbano dentro de características de qualidade adequadas à saúde, conforto e segurança dos habitantes, necessariamente, deverão perseguir a minimização das causas da poluição e a neutralização dos seus efeitos.
O fato é que as áreas urbanizadas acolhem em um território limitado uma grande concentração de pessoas, construções, indústrias, veículos motorizados, etc. em constante interação entre si e com o ambiente, gerando, além das alterações na base física, a poluição do solo, das águas e do ar.

O solo urbano, que de início sofre com a desfiguração da sua superfície, é afetado pelos resíduos das atividades humanas, especialmente pelos resíduos sólidos e efluentes líquidos (lixo e esgoto residenciais e industriais). Nas áreas urbanas, a poluição do solo está diretamente vinculada à poluição das águas, já que seus efeitos manifestam-se de forma mais evidente na contaminação de águas subterrâneas e superficiais pela infiltração de líquidos ou pelo carreamento de sujeira no processo de escoamento superficial das águas da chuva e no assoreamento dos corpos d'água (MOTA, 1981).

A poluição do ar nos centros urbanos resulta da emissão de gases, de vapores e do lançamento de partículas na atmosfera, associados às atividades humanas. A dispersão natural desses poluentes na atmosfera fica prejudicada a partir de uma certa escala urbana e a sua permanência na atmosfera pode causar danos ao ambiente e à população.

\section{Estabelecimento de usos permitidos e permissí- veis como contribuição para a sustentabilidade}

Os usos permitidos e permissíveis, por conta dos seus próprios conceitos, devem ser estabelecidos em função do uso predominante na zona considerada, visando a apoiá-lo e complementá-lo, conferindo um maior grau de conforto e eficiência funcional àquele segmento da cidade. $\mathrm{O}$ dinamismo econômico e social da zona, por outro lado, serão favorecidos com a diversificação de atividades que possam vir a se instalar nela, cabendo no entanto certa cautela no sentido de que os benefícios não se façam acompanhar por efeitos colaterais nocivos ao ambiente e à qualidade de vida dos usuários do espaço urbano.

Quando da seleção dos usos permitidos e permissíveis para uma determinada área da cidade é recomendável considerar os impactos previsíveis das atividades e adotar medidas que possam neutralizar eventuais conseqüências indesejáveis. Atabela 1 sugere algumas dessas medidas. 
LIMA, P. R. de; KRÜGER, E. L. Politicas públicas e desenvolvimento urbano sustentável

TABELA 1 - MEDIDAS A SEREM T OMADAS NADEFINIÇÃO DE USOS PERMITIDOS E PERMISSÍVEIS.

MEASURES TO BE TAKEN TO DEFINE WHAT CAN BE ALLOWED TO BE USED AND WHAT CANNOT BE.

\begin{tabular}{|c|c|}
\hline $\begin{array}{l}\text { Potencial de interferência no } \\
\text { espaço urbano }\end{array}$ & Medidas a serem adotadas \\
\hline $\begin{array}{l}\text { Geração de tráfego de } \\
\text { pedestres, veículos } \\
\text { particulares, de cargas e } \\
\text { transporte público e sua } \\
\text { distribuição ao longo do dia }\end{array}$ & $\begin{array}{l}\text { As atividades que são fontes geradoras de tráfego em volume capaz de comprometer a } \\
\text { malha viária da zona, a qualidade do ar, o conforto e a segurança devem ser distribuídas em } \\
\text { diversas zonas da cidade e classificadas como permissíveis, ensejando assim a análise de } \\
\text { cada caso em suas peculiaridades e a prescrição de medidas conciliatórias e mitigadoras } \\
\text { tais como vagas de estacionamento proporcionais ao fluxo gerado, pátio de manobras, } \\
\text { localização de acessos, arborização, sinalização, adequação do arruamento, implantação } \\
\text { de abrigos de ônibus, etc.; }\end{array}$ \\
\hline $\begin{array}{l}\text { Necessidade de } \\
\text { deslocamentos motorizados } \\
\text { para satisfazer necessidades } \\
\text { fora dos limites da zona }\end{array}$ & $\begin{array}{l}\text { Em função do uso predominante da zona, convém relacionar entre os usos permitidos e } \\
\text { permissíveis atividades que se complementem e que sejam cotidianamente utilizadas pelas } \\
\text { pessoas comuns. É o caso de supermercados, locadoras de vídeo, escolas, clínicas e tam- } \\
\text { bém de determinados tipos de indústrias, repartições públicas, oficinas e outros locais de } \\
\text { trabalho que, localizados próximos à habitação, podem ser acessados sem nenhuma ou } \\
\text { com menor utilização de veículos motorizados. }\end{array}$ \\
\hline $\begin{array}{l}\text { Características e volume de } \\
\text { efluentes líquidos, gasosos e } \\
\text { sólidos inerentes à atividade }\end{array}$ & $\begin{array}{l}\text { O enquadramento de atividades que gerem grande quantidade de efluentes deve ser prece- } \\
\text { dido de análise cuidadosa do potencial poluidor de seus resíduos, visando a autorizar ape- } \\
\text { nas a instalação daquelas cujos efluentes e subprodutos não ofereçam riscos à qualidade do } \\
\text { ambiente ou que possam ser submetidos a tratamento eficiente e seguro antes de ser lança- } \\
\text { dos ao ambiente ou às redes coletoras, mesmo assim na condição de uso permissível. }\end{array}$ \\
\hline $\begin{array}{l}\text { Produção de ruídos e } \\
\text { vibrações incômodos à } \\
\text { vizinhança, inclusive no } \\
\text { período noturno }\end{array}$ & $\begin{array}{l}\text { As atividades que produzam ruídos ou vibrações de intensidade capaz de causar incômodo } \\
\text { ou danos à saúde física e psicológica dos usuários da vizinhança, decorrentes da própria } \\
\text { atividade ou do acesso de usuários, devem ser enquadradas também como permissíveis, } \\
\text { fixando-se limites e medidas mitigadoras para liberação, especialmente em relação aos } \\
\text { afastamentos, implantação de barreiras vegetais e isolamento acústico. }\end{array}$ \\
\hline $\begin{array}{l}\text { Necessidade de grandes áreas } \\
\text { construídas e de áreas } \\
\text { abertas para estacionamento, } \\
\text { depósitos, etc. }\end{array}$ & $\begin{array}{l}\text { Para estas atividades (indústrias, comércio atacadista, hipermercados, concessionárias de } \\
\text { veículos, etc.), além de cuidados com a compatibilização com o sistema viário e de trans- } \\
\text { portes, convém prever medidas que possibilitem a absorção e a retenção das águas pluviais } \\
\text { coletadas e até mesmo a sua utilização para fins que não requeiram potabilidade, bem como } \\
\text { outras medidas que propiciem a redução da acumulação de calor nas edificações e pavi- } \\
\text { mentações. }\end{array}$ \\
\hline $\begin{array}{l}\text { Necessidade ou possibilidade } \\
\text { de funcionamento no } \\
\text { período noturno }\end{array}$ & $\begin{array}{l}\text { Atividades que necessitam funcionar no período noturno serão analisadas segundo a possi- } \\
\text { bilidade de minimização do incômodo à vizinhança, especialmente em relação ao ruído, } \\
\text { inclusive o provocado pelo acesso de veículos, funcionários e usuários. A lei deve estabe- } \\
\text { lecer os critérios de admissibilidade. Em alguns locais da cidade é interessante estimular o } \\
\text { funcionamento noturno de certas atividades, para maior conforto da população, distribuir } \\
\text { no dia o fluxo de veículos, melhorar a segurança das ruas, etc. }\end{array}$ \\
\hline Sazonalidade & $\begin{array}{l}\text { Atividades que funcionam com maior intensidade ou exclusivamente em um período do } \\
\text { dia ou do ano podem comprometer o dinamismo da zona, criar vazios temporários que } \\
\text { impliquem em ociosidade no uso da estrutura disponível ou mesmo na diminuição da segu- } \\
\text { rança, merecendo tratamento que não só neutralize seus efeitos negativos nos períodos de } \\
\text { "entressafra" como explorem positivamente suas potencialidades nos períodos favoráveis. }\end{array}$ \\
\hline
\end{tabular}

FONTE: LIMA (2002) 
LIMA, P. R. de; KRÜGER, E. L. Políticas públicas e desenvolvimento urbano sustentável

A deliberação sobre o tipo e características dos usos que uma determinada zona abrigará, como é típico no planejamento urbano, deve ser integrada com as decisões sobre densidade, sistema viário, etc. uma vez que a cidade também funciona de forma integrada. Como se verá a seguir, sua influência no controle das alterações climáticas e das diversas formas de poluição decorrentes da dinâmica urbana é significativa e deve ser considerada.

\section{Recomendações para redução de resíduos sólidos no ambiente urbano}

Com relação aos resíduos sólidos ou lixo doméstico, as diretrizes de controle do uso e ocupação do solo podem considerar a viabilidade técnica e econômica da coleta e disposição final, na área considerada, como parâmetro para o estabelecimento dos índices que determinam a densidadepopulacional.

No regulamento de edificações, é possível instituir a reserva de áreas para seleção e armazenamento temporário do lixo doméstico em edifícios e conjuntos habitacionais ou mesmo comerciais, proporcionais à estimativa de geração de resíduos compatíveis com a população usuária.

O volume diário de lixo produzido, como se sabe, varia em função da renda familiar, educação, hábitos de consumo, etc. Sabe-se também que as informações oficiais referem-se quase sempre apenas ao volume do lixo recolhido e estes fatos dificultam o estabelecimento de um volume de produçãoper capita médio mais preciso, porém, para fins de estimativa do volume gerado por uma determinada área da cidade, é possível relacionar volume diário de lixo recolhido com a população local.

Segundo esse critério, Sobral (1996) assinala que a cidade de São Paulo, no ano de 1993, produzia cerca de $0,874 \mathrm{~kg} /$ habitante/dia de lixo doméstico, valor bastante diferente da produção per capita de moradores de outros centros urbanos cujos hábitos culturais, renda e padrões sociais também são outros. Nas cidades americanas, esta produção chega à média de $2,4 \mathrm{~kg} / \mathrm{hab} / \mathrm{dia}$, enquanto em uma capital européia este número aproxima-se de 1,00 kg/ hab/dia e em Lima e em Cingapura este valor aproxima-se de $0,60 \mathrm{~kg} / \mathrm{hab} / \mathrm{dia}$, conforme a mesma autora. Em Curitiba considera-se a média de $0,55 \mathrm{~kg} / \mathrm{hab} / \mathrm{dia}$ ( SECRETARIADO MEIO AMBIENTE, 2002)

Além da variação de volume produzido, a composição do lixo doméstico também varia no tempo e entre uma cidade e outra. De acordo com estudos realizados pela Prefeitura Municipal de Curitiba, os resíduos sólidos domésticos recolhidos ao aterro sanitário da Cachimba e os resíduos recicláveis colhidos nos programas de coleta seletiva apresentam a composição mostrada na tabela 2 .

TABELA 2 - COMPOSIÇÃO DO LIXO DOMÉSTICO EM CURITIBA. DOMESTIC GARBAGE COMPOSITION IN CURITIBA.

\begin{tabular}{|c|c|c|}
\hline -Material & Aterto sanitárío & Kesídunos reciclávels \\
\hline Papel : papelãu & $03 \%$ & $35 \%$ \\
\hline Plístico bilme & $04 \%$ & $05 \%$ \\
\hline Pláscico dur'ọ & $02 \%$ & $(6 \%$ \\
\hline Tatas de flandres & $02 \%$ & $10 \%$ \\
\hline Vidro & $02 \%$ & $15 \%$ \\
\hline -Maléria orgûnica & $66 \%$ & - \\
\hline Rejeitos (horracha, isopor, tecidos, etc.) & $21 \%$ & $18 \%$ \\
\hline Sucila de ferto & & $07 \%$ \\
\hline Milais & - & $02 \%$ \\
\hline Madeira & - & $0 \% \%$ \\
\hline
\end{tabular}

FONTE: SECRETARIA MUNICIPAL DE MEIOAMBIENTE 
Partindo do indicativo de produção per capita, da composição aproximada do lixo doméstico apurada na cidade de Curitiba, ou ainda de levantamento direto destes mesmos indicadores no local, cotejados com a capacidade e características locais do serviço de coleta e destinação final do lixo, é viável estabelecer um limite máximo de unidades habitacionais que, em uma determinada área, poderão ter seu lixo coletado e convenientemente disposto.

Os efeitos deletérios mais impactantes do lixo doméstico sobre o ambiente ocorrem em áreas negligenciadas ou não atingidas pelo controle do uso e ocupação do solo, tais como as ocupações irregulares de fundos de vale e encostas, via de regra por populações de baixa renda. Por essa razão, a melhor contribuição do planejamento será voltar-se para a regularização dessas ocupações, introduzindo a seleção e coleta do lixo.

Naturalmente, a efetividade dos mecanismos de controle do uso e ocupação do solo em relação aos resíduos sólidos será mais significativa quando integrar um conjunto de medidas de operacionalização de coleta, seleção e tratamento do lixo, apoiadas em programas de conscientização e educação ambiental.

Resíduos sólidos dispostos de forma inadequada, acabam por comprometer a qualidade do solo e das águas, devido à percolação dos líquidos resultantes da decomposição da matéria orgânica, bem como pela contaminação direta e obstrução do leito dos corpos d'água pelo lixo depositado em suas margens ou para lá trazidos pelo escoamento superficial das águas da chuva.

\section{Recomendações para a minimização da poluição hídrica}

Na definição dos usos e índices de ocupação do solo com vistas a eliminar ou minimizar a poluição hídrica e seus efeitos nocivos ao ambiente urbano, segundo Mota (1981), é necessário considerar a capacidade da infra-estrutura sanitária existente ou projetada, a proteção e recarga do lençol freático e a preservação dos reservatórios e cursos d'água superficiais.

Os parâmetros de ocupação e uso do solo deverão ser definidos também de acordo com a natureza e quantidade dos efluentes líquidos gerados pelo uso residencial e atividades admitidas na área considerada, em função da capacidade do sistema de coleta e tratamento de esgotos e águas pluviais e da capacidade do ambiente de absorver e processar poluentes hídricos.
As atividades comerciais e industriais que necessitam descartar efluentes líquidos além do esgoto comum, como regra geral, deverão ser obrigadas a tratá-los adequadamente antes de lançá-los nas redes públicas ou no ambiente. Porém, a liberação da localização destas atividades em uma determinada zona deverá ser precedida de minuciosa análise sobre o volume de produção de efluentes, segurança do método de tratamento, etc. Quando do estudo da definição de tipos de indústrias que podem coexistir com outras atividades urbanas sem causar maiores danos ao ambiente, é conveniente considerar o potencial poluidor hídrico de cada atividade, além das demais implicações de caráter urbanístico. Das atividades industriais que, por razões de mercado, costumam localizar-se em meio a áreas urbanas adensadas, Mota (1981) menciona a equivalência entre a DBO (Demanda Bioquímica de Oxigênio) atribuída aos seus efluentes líquidos e o volume de esgoto produzido por uma determinada população, indicador que poderá ser útil na definição de usos permissíveis e permitidos, bem como dos critérios para a liberação da localização de atividades, especialmente na eventualidade de falha no tratamento daqueles efluentes. A tabela 3 aponta esta equivalência para tipos de indústrias mais freqüentes em áreas urbanizadas.

A carga poluidora dos esgotos domésticos gerados por uma determinada população pode ser estimada a partir da contribuição per capita de 200 litros/dia e a carga de DBO por habitante por dia, conforme Mota (1981) aponta, é igual a $54 \mathrm{~g} / \mathrm{hab} / \mathrm{dia}$.

Esses indicadores permitem avaliar a magnitude de um dos principais responsáveis pela poluição hídrica, tanto para dimensionar os sistemas de tratamento como para ajustar a expectativa de aumento da contribuição em determinada bacia hidrográfica à capacidade de assimilação do ambiente ou à capacidade do sistema de tratamento implantado ou projetado.

Os efluentes líquidos inerentes ao uso residencial, que, como se viu, tende a ocupar quase a metade das áreas urbanizadas, são os esgotos cloacais, as águas servidas e as águas pluviais captadas nos telhados, terraços e calçadas ou que de alguma forma são conduzidas até as redes de galerias ou diretamente à via pública.

O esgoto doméstico produzido no meio urbano, quando não é lançado diretamente no ambiente em situações extremas de falta de infra-estrutura, pode ser tratado por sistemas individuais de fossa séptica conjugada com sumidouro ou filtros, ou coletado por rede de esgoto para tratamento. 
LIMA, P. R. de; KRÜGER, E. L. Políticas públicas e desenvolvimento urbano sustentável

TABELA 3 - EQUIVALENTES POPULACIONAIS DE DBO POR TIPO DE INDÚSTRIA. DBO POPULATIONAL EQUIVALENTPER INDUSTRY TYPE.

\begin{tabular}{|c|c|c|c|}
\hline lïpo de Isıdústria & Puoduçầ diária & Lquival & populacional \\
\hline & & Lin hilbitumles & $\operatorname{Lrn} \operatorname{DBO}(\mathrm{g} / \mathrm{dia})$ \\
\hline Laticínios & Por 1.600 litros de leite & 30 a 80 & 1620 a 4320 \\
\hline Matadounros & P’or tọnęlada de boi em pé & 150 a 450 & 8100 a 24300 \\
\hline Carvajaria & Por 1000 litros de cervija & 300 i 2000 & 16200 is 108000 \\
\hline Lanilício & Por tonelada de lã & 1000 a 5000 & 54000 al 270000 \\
\hline Alv cjatriento de tecidos & Pur tondada de tecido & 250 al 300 & 13500 a 16200 \\
\hline lïnturaria & Por tondada de weido & 2000 a 3500 & 108000 a 189000 \\
\hline I avanderias & l'or' tonelada de roupas & 370 a 1000 & 19800 a 54000 \\
\hline
\end{tabular}

FONTE : INHOFF, KARL, 1966. In: MOTA(1989)

O tratamento individual em cada lote tem sua eficácia limitada pelas características do solo, por exigir espaço livre de terreno e cuidados de manutenção periódicos. Além disso, esse tipo de tratamento oferece risco de contaminação do lençol freático e corpos d'água, conforme comentado em item anterior.

Assim, em áreas da cidade onde não existe rede de coleta de esgoto, é necessário estabelecer dimensões mínimas de lote, taxa de ocupação e coeficiente de aproveitamento que restrinjam as respectivas densidades populacionais no futuro a um número compatível com as limitações próprias dos métodos de tratamento individual.

Essas limitações dizem respeito às características geológicas do terreno, sua permeabilidade, a profundidade do lençol freático, declividade, etc. Segundo Mota (1981), o tratamento de esgoto por fossa e sumidouro deverá ser evitado nas seguintes situações:

- solos com alta permeabilidade (coeficiente de absorção superior a $1401 / \mathrm{m}^{2} /$ dia);

- solos com baixa permeabilidade (coeficiente de absorção inferior a $251 / \mathrm{m}^{2} /$ dia) ;

- profundidade do lençol freático que não permita manter uma distância de $1,50 \mathrm{~m}$ entre o fundo do sistema de absorção e o nível máximo do lençol freático;

- terrenos com declividade superior a 20\%;

- distância inferior a 30,00m de poços e cursos d'água;

- presença de rochas impermeáveis próximas à superfície do solo, a menos de 1,80m.

Porém, enquanto o atendimento por rede de coleta e tratamento de esgoto não beneficia a totalidade da população urbana, não é possível desconsiderar a solução fossa séptica / sumidouro no planejamento do solo urbano, observando-se as limitações mencionadas.

Para a estimativa do volume de esgoto doméstico em uma determinada área, o autor citado considerou, para o caso de uso residencial, a contribuição de 200 litros por pessoa por dia e, em edifícios comerciais e de serviços, adotou a contribuição de 50 litros por pessoa por dia.

Vale lembrar que o volume de esgotos e águas servidas que chegam à rede coletora ou aos sistemas de tratamento individual pode ser reduzido por meio de programas de racionalização do consumo de água, especialmente com o melhor rendimento das caixas de descarga e o reaproveitamento da água utilizada para lavar roupas, nas banheiras e chuveiros para uso na descarga. 


\section{Recomendações para a redução da poluição atmosférica}

Comparada com a poluição do solo e a poluição hídrica, talvez a forma mais evidente de poluição gerada no meio urbano seja a atmosférica, uma vez que seus efeitos são mais perceptíveis no dia a dia dos cidadãos, pelo desconforto e danos à saúde, pela pátina de sujeira que se deposita sobre edifícios, árvores, monumentos, etc., bem como pela convivência diária, forçada e quase inevitável com uma de suas principais fontes, a emissão de gases dos escapamentos de veículos automotores.

O esforço no sentido de minimizar a poluição do ar e seus efeitos no meio urbano, pelo planejamento e controle do uso e ocupação do solo urbano, deverá considerar especialmente a localização das fontes poluidoras, o tipo e quantidade de poluentes, a concentração de poluentes na área considerada, o transporte e dispersão dos poluentes na atmosfera (МОтА, 1981), bem como aqueles fatores que condicionam a movimentação do ar e a acumulação de calor em edifícios, pavimentos, etc.

Como as principais fontes produtoras de poluentes atmosféricos no meio urbano são os veículos automotores, os processos industriais, a queima de combustíveis em fornos, aquecedores, caldeiras, etc., bem como as partículas sólidas em suspensão, o controle envolverá necessariamente a redução da emissão de poluentes e a neutralização dos efeitos negativos sobre a saúde humana e o meio ambiente, principalmente pela preservação das condições de ventilação dos espaços externos às edificações.

Quando da definição dos usos permitidos, permissíveis e proibidos, além da exigência de tratamento adequado dos efluentes gasosos para liberação de atividades, é possível influir na minimização dos efeitos da poluição atmosférica das seguintes maneiras:

- incluindo a avaliação das características das emissões gasosas na seleção das atividades adequadas para uma determinada zona;

- distribuindo as chamadas fontes localizadas de poluição do ar no espaço urbano, de modo que os ventos dominantes operem naturalmente a dispersão dos poluentes, evitando a condução de substâncias nocivas e odores desagradáveis para áreas densamente habitadas;

- reduzindo a geração de deslocamentos motorizados por meio da diversificação de atividades per- mitidas e permissíveis, de modo a suprir o maior número possível de necessidades nas proximidades da residência.

Na elaboração dos índices de ocupação do solo é interessante incluir entre os efeitos desejados a criação de condições propícias à adequada movimentação do ar, à dispersão de poluentes, à amenização do calor refletido pelos edifícios e pela pavimentação, assim como o controle da canalização e velocidade do vento e da formação de ilhas de calor.

Para tanto, é conveniente que os valores limites de recuo frontal, afastamentos e altura máxima das edificações sejam estabelecidos de forma diferenciada, considerando a direção dos ventos dominantes, a orientação da testada do lote e a largura da caixa da rua.

As taxas de ocupação e coeficientes de aproveitamento estabelecidos para cada zona deverão induzir uma distribuição da densidade de ocupação que não provoque, a partir do efeito de armazenamento térmico das edificações, campos térmicos diferenciados que, segundo Danni-Oliveira (2000), tendem a propiciar o confinamento dos poluentes lançados pelo tráfego intenso.

Em recente estudo tendo como objeto a cidade de Porto Alegre, Mascaró (2001a) menciona a necessidade de assegurar uma permeabilidade ao ar mínima de $30 \%$ pela adoção de afastamentos laterais determinados em função da altura do edifício e da densificação máxima de até 100 economias/ha, o que, em zonas predominantemente residenciais, corresponde a aproximadamente $500 \mathrm{hab} / \mathrm{ha}$.

A legislação urbanística do município de Curitiba introduziu em janeiro de 2000 o afastamento das divisas variável em função da altura do edifício, acima do $2^{\circ}$ pavimento, na proporção igual a $\mathrm{H} / 6$ (um sexto da altura) nas zonas de densidades mais elevadas.

Esta medida tem o condão de evitar a formação de "canyons" artificiais nas áreas urbanas, liberando uma quantidade de área livre para a movimentação do ar entre as edificações e para a insolação dos ambientes externos e internos, com evidentes benefícios para a qualidade e salubridade do espaço urbano.

O recuo frontal precisa guardar uma relação com a largura das ruas e também com a altura dos edifícios para, quando necessário, aumentar a largura do canal de passagem do ar em movimento, contribuindo desse modo para a redução da sua velocidade, diminuindo a formação de redemoinhos e a suspensão de material particulado depositado no solo, árvores e edificações e outros inconvenientes. 
LIMA, P. R. de; KRÜGER, E. L. Políticas públicas e desenvolvimento urbano sustentável

A prática corrente de diferenciar a medida do recuo frontal dos dois primeiros pavimentos nas zonas centrais da cidade, que se deve à conveniência urbanística de utilizar o pavimento térreo e sobreloja para atividades comerciais e de serviço, acaba elevando os efeitos benéficos do recuo frontal relativamente à ventilação para uma faixa acima da altura destes dois pavimentos, mas ainda assim favorece a insolação das fachadas dos primeiros pavimentos e da própria rua.

As medidas recomendadas para reduzir a poluição atmosférica a partir dos mecanismos de controle da ocupação do solo favorecem também os esforços para redução do consumo de energia na iluminação interna e no condicionamento térmico das edificações, como se verificará a seguir.

\section{Recomendações para racionalização da utilização de energia}

Os cuidados na elaboração dos parâmetros de uso e ocupação do solo que objetivam a minimização da desqualificação do ambiente urbano, até aqui apresentados didaticamente e agrupados segundo sua ação mais efetiva sobre a poluição hídrica, atmosférica e em relação aos resíduos sólidos, podem e devem no seu conjunto resultar em redução do uso de energia para atender às necessidades de conforto, salubridade e funcionalidade da vida urbana.

As discussões sobre a sustentabilidade urbana incluem obrigatoriamente a questão da eficiência energética e das práticas capazes de manter ou melhorar o grau de qualidade de vida urbana sem aumentar o consumo de energia. Algumas dessas práticas, tais como a maior utilização da iluminação natural, redução do uso de aquecedores, ventiladores e condicionadores de ar e redução de deslocamentos motorizados, podem ser estimuladas e viabilizadas por meio dos mecanismos de controle do uso e ocupação do solo.

Os coeficientes de aproveitamento e taxas deocupação dimensionados adequadamente e aliados a uma cuidadosa distribuição espacial das atividades no espaço da cidade poderão evitar ou diminuir a necessidade de deslocamentos motorizados e tornar mais eficazes o planejamento e a operação do serviço de transporte coletivo, bem como as políticas de desestímulo ao uso do transporte individual.

O recuo frontal e os afastamentos das divisas mínimos e altura máxima, estabelecidos segundo as recomendações anteriores, auxiliarão na racionalização do consumo de energia quando contribuírem para:
- garantir o maior número de horas de insolação nas fachadas dos edifícios, permitindo o aproveitamento da iluminação natural por mais tempo e reduzindo a necessidade de aquecimento dos ambientes por meios artificiais nos períodos de frio ou de refrigeração nos períodos de temperatura ambiente elevada;

- viabilizar a movimentação do ar junto às paredes de entorno da edificação, melhorando a ventilação dos ambientes internos, reduzindo a acumulação de calor nas paredes externas e, deste modo, diminuindo a necessidade do uso de ventiladores, condicionadores de ar e secadoras de roupas.

O melhor aproveitamento desses princípios na elaboração dos valores dos índices urbanísticos requer estudos específicos para cada município que considerem as peculiaridades de localização e clima da região, a orientação solar do arruamento, bem como a situação real de ocupação já existente.

\section{Incentivos à promoção da sustentabilidade urbana}

Além das medidas sugeridas, a política de uso do solo poderá também oferecer a flexibilização de algum dos parâmetros de ocupação do solo em troca de medidas que concorram para a eficiência energética na edificação, a utilização racional da água tratada e a separação e redução do volume de lixo coletável, desde que a operação não resulte em prejuízo ao ambiente urbano.

Exemplos dessa possibilidade são os mecanismos adotados por alguns municípios para induzir o proprietário ou construtor a incorporar em seus projetos determinadas soluções arquitetônicas ou promover destinações à parte do imóvel que contribuam para a preservação da memória, da identidade cultural da cidade ou para atingir algum objetivo relevante para a comunidade, como a preservação de bosques e paisagens notáveis. É uma forma engenhosa de viabilizar uma iniciativa positiva sem recorrer à imposição rigorosa de uma lei, oferecendo uma vantagem atrativa ao empreendedor e obtendo em troca o resultado urbanístico ou ambiental desejado.

Até para fugir das contestações judiciais, o município poderá flexibilizar algum dos índices urbanísticos em troca da introdução de tecnologias ou soluções arquitetônicas que concorram para a redução do consumo de ener- 
gia, de água tratada ou outros resultados benéficos à preservação do ambiente urbano, as quais deverão ser relacionadas e valoradas por meio de um instrumento legal.

Nessa linha estratégica, uma lei municipal poderia instituir um programa de estímulo à construção sustentável, oferecendo coeficiente de aproveitamento ou número máximo de pavimentos diferenciados aos proprietários dispostos a implementar soluções tais como:

- Redes separadas de captação de esgotos cloacal e águas servidas;

- Sistema de captação, armazenamento e utilização de águas da chuva para fins que não requeiram potabilidade;

- Rede de água não tratada para uso na descarga dos vasos sanitários;

- Sistema solar para aquecimento de água;

- Utilização de materiais de construção de baixo conteúdo energético;

- Área adequada para estocagem temporária de resíduos sólidos recicláveis;

- Plantação de árvores nas áreas de recuo;

- Implantação de jardins, hortas e pomares na cobertura dos edifícios residenciais;

- Outras soluções que, comprovadamente, impliquem em economia de recursos naturais não renováveis (estrutura de madeira certificada ou de reflorestamento, materiais reciclados ou reutilizados, etc.).
Esta mesma proposição pode ser adotada, com menor risco de desvirtuamento por efeito da corrupção ou de avaliação incorreta do benefício ambiental na troca de vantagens, utilizando isenções ou reduções de tributos municipais.

\section{Possibilidades de políticas públicas para controle do uso e ocupação do solo intervirem na promo- ção da sustentabilidade urbana}

Na sua área de influência sobre o futuro da cidade, as políticas públicas que orientam o planejamento e controle do uso e ocupação do solo urbano precisam ser adequadas às condições peculiares de cada cidade e mesmo de cada zona, de modo que contribuam para o aprimoramento da qualidade do meio ambiente urbano, no presente e no futuro.

A aplicação prática das potencialidades apontadas pode ser mais efetiva quando se identifica previamente os problemas ambientais sobre os quais se pretende atuar. Nesse sentido, Lima (2002) relaciona uma série de situações desejáveis ou objetivos ambientais que concorrem para a sustentabilidade urbana e as associa a medidas acautelatórias e recomendações que, se incorporadas às políticas e ações públicas no presente, poderão minimizar parte significativa dos subprodutos do crescimento urbano que causam a degradação ambiental (tabela 4).

TABELA 4 - OBJETIVOS AMBIENTAIS E ESTRATÉGIAS PARAALCANÇÁ-LOS. ENVIRONMENTAL GOALS AND STRATEGIESAND HOW TO REACH THEM

\begin{tabular}{|c|c|}
\hline Objetivo ambiental & Estratégia \\
\hline $\begin{array}{l}\text { Redução da poluição do solo e } \\
\text { da água pelos resíduos sólidos } \\
\text { urbanos }\end{array}$ & $\begin{array}{l}\text { - Intervenção nas áreas de ocupação irregular em fundos de vale e nascentes; } \\
\text { - Utilização da bacia hidrográfica como referência na delimitação das zonas; } \\
\text { - Definição e distribuição da densidade demográfica também em função da viabilidade } \\
\text { do serviço de coleta e destinação final do lixo urbano; } \\
\text { - Exigência no Regulamento de Edificações de área adequada para seleção e arma- } \\
\text { zenamento temporário do lixo reciclável. }\end{array}$ \\
\hline $\begin{array}{l}\text { Redução da poluição do solo e } \\
\text { das águas subterrâneas }\end{array}$ & $\begin{array}{l}\text { - Restrição à instalação de atividades que gerem efluentes líquidos contaminados por } \\
\text { gasolina, bactérias coliformes, compostos químicos e outros contaminantes capazes de } \\
\text { permanecer longo tempo e se deslocar no subsolo por grandes distâncias; } \\
\text { - Dimensões mínimas de lotes suficientes para abrigar sistemas de tratamento individual } \\
\text { de esgoto, estabelecidas em função da permeabilidade do solo local; } \\
\text { - Taxa de ocupação adequada para liberar áreas livres de construção no lote para a mes- } \\
\text { ma finalidade; }\end{array}$ \\
\hline
\end{tabular}




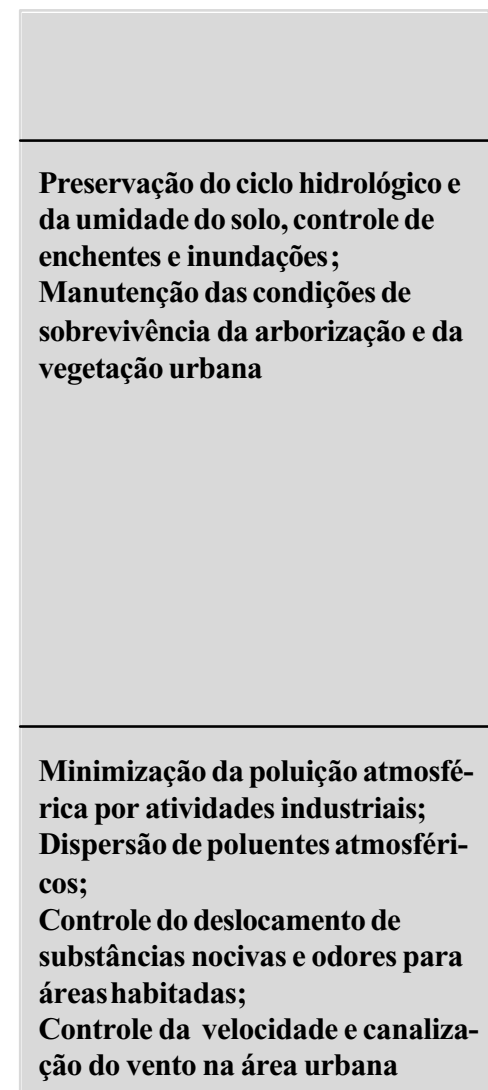

Redução da emissão de $\mathrm{CO}_{2}$ por veículos automotores

Prevenção à formação de ilhas de
calor;
Dispersão dos efeitos do
armazenamento térmico das
edificações

- Coeficiente de aproveitamento que determine uma densidade populacional compatível com sistema de tratamento individual de esgoto, na ausência de rede coletora, ou com a viabilidade técnica e econômica do sistema de coleta e tratamento.

- Previsão de percentual e localização de áreas permeáveis, livres de pavimentação e edificação, quando da delimitação das zonas, com destinação específica para esporte, lazer, pomar, etc;

- Delimitação na lei de zoneamento das faixas de preservação ao longo dos cursos d'água e fundos de vale, estabelecidas em função da área da bacia de contribuição, prevendo a recomposição da mata ciliar, equipamentos de lazer e esporte, quando em área pública;

- Taxa de permeabilidade definida em função das características do solo local;

- Taxa de ocupação para o pavimento térreo inferior a 75\%, sempre que possível;

- Estímulo à utilização de revestimentos permeáveis de piso em áreas de lazer, pátios de manobra, estacionamentos, acessos de veículos, etc;

- Determinação da retenção temporária das águas pluviais coletadas em edifícios, para retardar o lançamento deste volume às galerias, facultando o aproveitamento da água da chuva retida nas edificações;

- Restrição à utilização do subsolo para garagem em áreas onde o nível do lençol freático é próximo da superfície.

- Avaliação das características das emissões gasosas das atividades classificadas como "uso permitido, permissível ou proibido", estabelecendo a obrigatoriedade de tratamento no caso de emissões de substâncias nocivas;

- Distribuição espacial das atividades potencialmente poluidoras do ar também em função da direção dos ventos dominantes;

- Recuo frontal acima do $2^{\circ}$ pavimento diferenciado em função da largura da rua e da direção dos ventos dominantes;

- Afastamentos laterais definidos em função da altura do edifício e da direção dos ventos dominantes.

- Diversificação de atividades permitidas e permissíveis em cada zona, de modo a reduzir deslocamentos motorizados para satisfazer necessidades, trabalhar, estudar, etc.

- Coeficientes de aproveitamento que determinem densidade bruta de ocupação máxima igual ou inferior a 100 economias/ha ou $500 \mathrm{hab} / \mathrm{ha}$;

- Distribuição e diversificação das densidades de ocupação no espaço urbano;

- Recuo frontal, afastamentos laterais e de fundos definidos em função da altura da edificação, da orientação solar da testada do lote e da direção dos ventos dominantes, garantindo permeabilidade ao ar mínima de $30 \%$.

\begin{tabular}{l}
\hline $\begin{array}{l}\text { Redução do consumo de combustí- } \\
\text { veis }\end{array}$ \\
\hline $\begin{array}{l}\text { Redução do consumo de energia } \\
\text { elétrica; Diminuição da necessidade } \\
\text { do uso de iluminação artificial ; } \\
\text { Minimização da necessidade de } \\
\text { condicionamento térmico artificial }\end{array}$ \\
FONTE: LIMA (2002)
\end{tabular}

- Diversificação de atividades permitidas e permissíveis em cada zona, de modo a reduzir deslocamentos motorizados para satisfazer necessidades, trabalhar, estudar, etc.

- Compatibilização entre a distribuição espacial de atividades geradoras de tráfego intenso e os sistemas viário e de transporte coletivo.

- Recuo frontal e afastamentos dimensionados em função da orientação solar e altura da edificação;

- Possibilidade de flexibilização de alguns parâmetros de ocupação do solo como estímulo à adoção de soluções sustentáveis na edificação, na fase de construção e operação. 
LIMA, P. R. de; KRÜGER, E. L. Politicas públicas e desenvolvimento urbano sustentável

As recomendações acima, embora não esgotem o tema, ajudarão a consolidar, acrescentar ou estimular a perspectiva da sustentabilidade como mais uma meta de desenvolvimento dentre as tantas que as políticas públicas de uso e ocupação do solo se propõem a perseguir, apenas trazendo à tona potencialidades dos tradicionais instrumentos de planejamento, normatização e controle do uso e ocupação do solo inexploradas mas capazes de conduzir aos objetivos listados.

\section{Considerações finais}

As políticas públicas relativas ao uso e ocupação do solo podem, efetivamente, ampliar sua eficácia no processo de condução do desenvolvimento urbano, incorporando às suas finalidades o propósito de contribuir para a sustentabilidade das cidades brasileiras e, mais especificamente, de evitar ou minimizar a interferência negativa do crescimento urbano na qualidade do ambiente.

\section{REFERÊNCIAS}

ACSELRAD, H. Discursos da sustentabilidade urbana. Revista Brasileira de Estudos Urbanos e Regionais, Rio de Janeiro, n 1, p. 79-89, maio 1999.

BEZERRA, M. C. L.; FERNANDES, M. A. (Coords.). Cidades sustentáveis: subsídios à elaboração da Agenda 21 brasileira. Brasília, Ministério do Meio Ambiente, 2000.

DANNI-OLIVEIRA, I. M. Considerações sobre a poluição do ar em Curitiba- PR face a seus aspectos de urbanização. $R A E^{\prime} G A$ - $O$ espaço geográfico em análise, $\mathrm{n} 4$, ano IV, $\mathrm{p}$. 101-109, 2000.

FERRARI, C. Curso de Planejamento Municipal IntegradoUrbanismo. São Paulo: Livraria Pioneira, 1979.

JACOBI, P. Meio ambiente urbano e sustentabilidade: alguns elementos para reflexão. Meio Ambiente, desenvolvimento sustentável e políticas públicas. São Paulo. Cortez. Recife. Fundação Joaquim Nabuco, 2002. p.384 - 390.

KRÜGER, E. L.; ROSSI, F. A. Análise comparativa em termos de conforto térmico em localidades da Região Metropolitana de Curitiba. In: NUTAU-2002, 2002, São Paulo. Anais... São Paulo: Núcleo de Pesquisa em Tecnologia da Arquitetura e Urbanismo (CD-ROM) .
Como se verifica na tabela 5, algumas das estratégias sugeridas contribuem para o atingimento de mais de um objetivo, evidência de que estas terão maior influência na manutenção ou aprimoramento da qualidade do espaço urbano. Esse fato reforça a importância de uma abordagem sistêmica e integrada na elaboração das políticas públicas, diretrizes e planos setoriais de modo a obter o máximo de resultados - também sob o ponto de vista ambiental-das potencialidades transformadoras de cada ação ou investimento público.

A exemplo das que tratam da organização territorial, as políticas públicas podem e devem tornar-se instrumentos da construção de um processo de desenvolvimento urbano sustentável, incluindo em seus objetivos e metas a preocupação com a sustentabilidade e incorporando às suas motivações a necessidade de interação entre justiça social, qualidade de vida, equilíbrio ambiental e, como comenta Jacobi (2002), a necessidade de desenvolvimento com respeito à capacidade de suporte da cidade.

LIMA, P. R. Uma análise dos parâmetros de uso e ocupação do solo na promoção da sustentabilidade urbana. Curitiba, 2002. Dissertação (Mestrado em Tecnologia) - PPGTE, CEFET PR.

LOMBARDO, M. A. O clima e a cidade. In: ENCONTRO NACIONAL DE CONFORTO NO AMBIENTE CONSTRUÍDO, 4, 1977, Salvador. Anais ... Salvador, ANTAC, 1997. p. 59-60.

MASCARÓ, J.; MASCARÓ, L. Iluminação natural. Programa PREAMBE, UFRGS, 2001a.

MOTA, S. Planejamento urbano e preservação ambiental. Fortaleza: UFC-Proedi, 1981.

ROMERO, M. A. B. Princípios bioclimáticos para o desenho urbano. São Paulo: Projeto, 1988.

SECRETARIA DO MEIO AMBIENTE DE CURITIBA. Gerenciamento dos resíduos sólidos urbanos no Município de Curitiba. Curitiba, 2002. Relatório Técnico.

SOBRAL, H. R. O meio ambiente e a cidade de São Paulo. São Paulo: Makron Books, 1996. 